\title{
Ivanna Rosi, Les Masques de Chateaubriand. Liberté et contraintes de la représentation de soi
}

\section{Yann Mortelette}

\section{(2) OpenEdition}

10 Journals

\section{Édition électronique}

URL : http://journals.openedition.org/studifrancesi/2184

DOI : 10.4000/studifrancesi.2184

ISSN : 2421-5856

Éditeur

Rosenberg \& Sellier

\section{Édition imprimée}

Date de publication : 1 avril 2014

Pagination : 156-157

ISSN : 0039-2944

\section{Référence électronique}

Yann Mortelette, «Ivanna Rosi, Les Masques de Chateaubriand. Liberté et contraintes de la représentation de soi », Studi Francesi [En ligne], 172 (LVIII | I) | 2014, mis en ligne le 01 avril 2014, consulté le 18 septembre 2020. URL : http://journals.openedition.org/studifrancesi/2184 ; DOI : https://doi.org/ 10.4000/studifrancesi.2184

Ce document a été généré automatiquement le 18 septembre 2020.

\section{(c)}

Studi Francesi è distribuita con Licenza Creative Commons Attribuzione - Non commerciale - Non opere derivate 4.0 Internazionale. 


\title{
Ivanna Rosi, Les Masques de Chateaubriand. Liberté et contraintes de la représentation de soi
}

\author{
Yann Mortelette
}

\section{RÉFÉRENCE}

IVANNA ROSI, Les Masques de Chateaubriand. Liberté et contraintes de la représentation de soi, texte traduit de l'italien par Chrystelle JACQUES, Josiane TOURRES et Claire vovelle, Paris, Classiques Garnier, 2012, pp. 308.

1 Cet ouvrage est la traduction française du livre d'Ivanna Rosi Le Maschere di Chateaubriand, publié à Florence par les éditions Le Lettere en 2010. Il réunit, sous une forme remaniée, douze études parues dans des revues, des actes de colloques ou des éditions de textes de 1993 à 2010, et en fait découvrir trois autres (René, Chactas, le voyageur, pp. 87-93; L'historicisation du moi, pp. 135-147; Rancé, pp. 285-299). Préférant à une analyse systématique des «approches ponctuelles de certains thèmes et de certaines œuvres, à savoir Les Natchez, avec René et Atala, l'Essai historique sur les Révolutions, les Mémoires d'outre-tombe et la Vie de Rancé» (p. 13), Ivanna Rosi commente la façon dont Chateaubriand se met en scène dans ses écrits.

2 Consacrée à René, la première partie examine les liens de ce personnage avec la patrie utopique des Natchez, «ce Tahiti sentimental, ou plutôt ce Clarens américain» (p. 24). Ivanna Rosi observe que, dans Les Natchez, le thème du cœur reflète à la fois la sensibilité policée du XVIII ${ }^{e}$ siècle et les passions primitives des Indiens. Dans le chapitre «Le frère d'Amélie», elle relève les indices textuels tendant à prouver que René nourrit consciemment un amour incestueux pour sa sœur et qu'il est animé d'un esprit de rébellion contre la société et contre Dieu. Dans René, la scène au cours de laquelle Amélie prononce ses vœux religieux lui apparait comme «une sorte de mariage à rebours» (p. 82). La comparaison de René et de Chactas, de l'exilé volontaire et du 
voyageur nostalgique, lui permet de souligner les états d'âme contradictoires de l'écrivain.

3 La deuxième partie présente l'évolution des idées de Chateaubriand entre la publication de l'Essai en 1797 et celle des Mémoires d'outre-tombe. Si les notes ajoutées à l'Essai en 1826 s'efforcent d'en corriger le pessimisme social et l'anticléricalisme, elles témoignent pourtant de la permanence d'une poétique de la discontinuité et du fragment, dont les Essais de Montaigne ont peut-être fourni le modèle. Ivanna Rosi décèle dans ces notes des traces de «l'athéisme religieux des Mémoires, placé entre l'Ecclésiaste et la perception angoissée et solennelle du vide de l'outre-tombe» (p. 111). Dans la quatrième partie des Mémoires reparaissent certains thèmes de l'Essai, comme le constat de l'absurdité de l'histoire; mais le ton employé par l'écrivain n'est plus le même: «Le grotesque est l'habit dont il affuble sa vieillesse, comme le pathétique du "malheureux" était le masque de sa jeunesse» (p. 112). En comparant les différents portraits de Malesherbes et de Francis Tulloch dans l'Essai et dans les Mémoires, Ivanna Rosi montre comment Chateaubriand abandonne la sensibilité $\mathrm{du}$ XVIII ${ }^{\mathrm{e}}$ siècle pour adopter le point de vue objectif de l'historien. Appliquant ce procédé de distanciation à l'évocation de sa propre personnalité, le mémorialiste brosse souvent un tableau historique de sa vie au lieu d'exprimer son intériorité. On aurait aimé savoir quels traits psychologiques révèle cette tendance à l'historicisation du moi.

4 La troisième partie étudie la rhétorique de l'allusion que l'écrivain met en place dans ses Mémoires afin d'évoquer les tentations récurrentes du désir et de la mort. À l'instar de Rousseau, Chateaubriand utilise l'autodérision pour se mettre en valeur. Dans les chapitres «L'instinct de la patrie» et «L'instinct du voyage», Ivanna Rosi s'intéresse aux «deux polarités opposées du moine et du chevalier errant» (p. 207) qui coexistent chez l'écrivain. Après avoir analysé la valeur symbolique de certains thèmes (l'arbre et le navire, le paysan et le matelot) et de certains lieux (Combourg et la Vallée-aux-Loups, l'Angleterre et la Suisse, Rome et Venise), elle remarque que, lors de son voyage en Amérique, Chateaubriand rêve de trouver le bonheur en arrêtant ses pérégrinations. Enfin, à travers les portraits critiques que le mémorialiste fait de Napoléon, des rois de France et de Rancé, elle démasque ses contradictions à l'égard du monde de l'action, du pouvoir politique et de la religion. 